\title{
Evaluating Satellite-Based Measurements for Mapping Air Quality in Ontario, Canada
}

\author{
J. Tian and D. M. Chen \\ Department of Geography, Queen's University, Kingston, ON K7L 3N6, Canada
}

\begin{abstract}
This paper presents a study of examining the correlation between the satellite observations and the ground-based measurements of air quality in Ontario, Canada. Two atmospheric parameters-total ozone burden (TOB), and aerosol optical depth (AOD) data-were extracted from the Moderate Resolution Imaging Spectroradiometer (MODIS) atmosphere data products. TOB and AOD were then compared with the coincident ground-based ozone concentration (GOC) and fine particular matter (PM2.5) in summer and winter seasons, respectively. The comparison results showed that AOD was most strongly related with coincident hourly PM2.5 in summer, while TOB and coincident hourly GOC have shown their fairly strong correlation in winter. The correlation between MODIS measurement and ground monitoring data in summer seems independent from those in winter. This is the first study to demonstrate that the correlation between the satellite measurement and ground monitoring data varied in different seasons. The air quality distribution obtained from satellite images has a much better correspondence with the regional morphology than those interpolated from ground measurements.
\end{abstract}

Keywords: Air pollution, correlation, ground-measurement, MODIS, remote sensing

\section{Introduction}

Air quality has increasingly become a great concern to the public, researchers, and policy-makers, as extensive research has demonstrated that air pollutants affect the health of humans and animals, damage vegetation and materials, reduce visibility and solar radiation, and affect weather and climate (Arya, 1998). Accurate mapping of air quality and its seasonal and annual changes is important for the evaluation of the current air dispersion modeling, air pollution control regulations, and other environmental and climate change related activities. Traditionally, two general approaches to mapping air pollution can be identified: spatial interpolation and air dispersion modelling (Briggs, 1992). The former approaches estimate the value of pollution concentration at unsampled locations in an area of interest by interpolating the measurements from the sampled stations (Ionescu et al., 2000; Jerrett et al., 2005). In contrast, the latter approaches intend to model the dispersion and/or diffusion of air pollutants, mainly as a more complicated meteorological and chemical process (Hass et al., 1997; Ulke and Andrade, 2001; Villasenor et al., 2001).

Most of the air quality data that we have currently used are interpolated from the data collected from a limited number of measuring stations located mainly in cities or estimated by the numerical air dispersion models. However, air quality is highly variable across region. Recent research indicates that periodic observations made by the current satellites may efficiently complement ground measurements. For example, efforts have been made to map concentration in suspended par-

\footnotetext{
* Corresponding author: chendm@post.queensu.ca
}

ticulates (PM10) using TM image (Ung et al., 2001). Wald (1999) examined correlation between ground air quality parameters and Landsat TM measurements in thermal infrared band. Their study suggests that $\mathrm{SO}_{2}$ was apparently correlated to the temperature although the number of measurements was too small to be conclusive. In another study of using TM images, Ung et al. (2003) found a linear correlation between reflectance derived from Landsat satellite and the integrated concentration of suspended particular PM10.

More articles on MODIS applications in air quality study are found in the literature, possibly because: (1) MODIS has dedicated atmosphere products (e.g. aerosol products) that include more straightforward parameters for air quality studies; (2) MODIS has a daily global coverage and is freely and easily accessible by the worldwide researchers. Engel-Cox et al. (2004) qualitatively and quantitatively evaluated the integrated use of ground-based and satellite data for air quality monitoring at urban and regional scales. They used a six month time period in 2002 to compare US Environmental Protection Agency monitoring data and MODIS atmosphere data. The great correlation between AOD and PM2.5, coupled with implications from qualitative analysis, indicated that MODIS had tremendous potential to support EPA and other agencies to monitor air quality. Similar study was conducted by Hutchison et al. (2005) with a focus on correlating MODIS AOD with ground-based PM2.5 observations across Texas. By aggregation of pixels in the MODIS AOD images, higher correlations were achieved. A bin-averaged approach results in high correlations as well, indicating smoothing of the data sets was needed to produce high correlations, which eliminated the possibility of using this approach in a real-time forecast system. Hutchison et al. (2004) intended to predict air quality by 


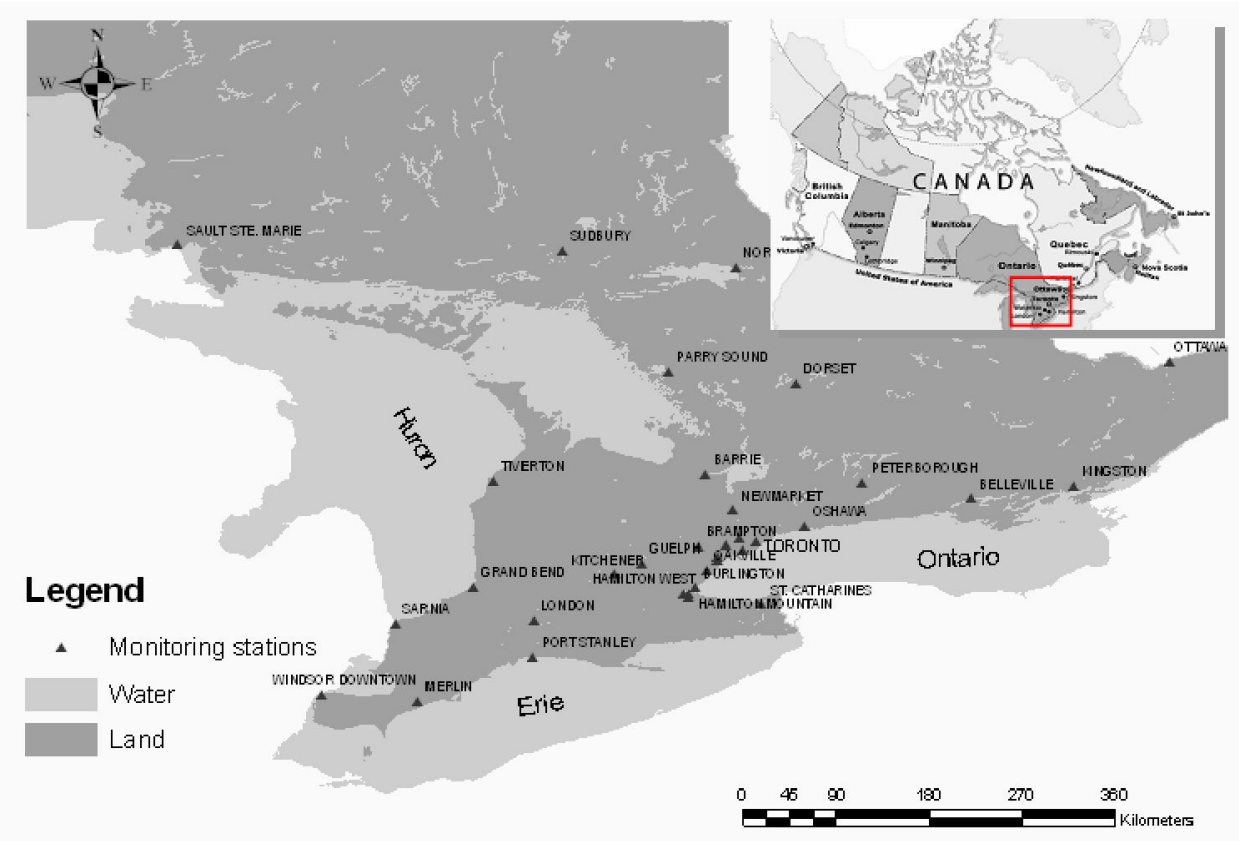

Figure 1. The study area and the location of monitoring stations.

using MODIS data with trajectories in a trend forecast. The proposed method was recognized as being very useful when the transient pollution can be isolated from local sources.

Most of the studies investigating the correlations between AOD and PM2.5 provide general statements of how strong or weak the correlations are in the study areas. They do not differentiate the correlations in different seasons. Furthermore, MODIS aerosol products include a parameter of Total Ozone Burden (TOB). Few studies were found in the literature investigating the relationship between ground ozone concentration (GOC) and TOB at regional or local scale. Actually, MODIS temperature and water vapour profile product provides a great resource of TOB values for both day and night on a daily basis. Although the stratosphere has the majority of the ozone in an atmospheric column, it is valuable to look at the possible relation between TOB and GOC, even just as a residual.

This paper intends to explore the suitability of using MODIS atmosphere products as an ancillary source for monitoring regional air quality to the ground network of monitoring stations. The AOD and TOB parameters were extracted from their corresponding products. They were then compared with the ground-based PM2.5 and GOC respectively. The season-based analysis was performed for both comparisons, and diurnal analysis was performed for TOB vs. GOC. City specific analysis was also conducted for all the cities with monitoring stations across Ontario. The correlation coefficients of the stations were spatially interpolated to generate a correlation surface, implying the variation of correlation across the region.

\section{Data Description, Data Acquisition, and Pre-Processing}

\subsection{Study Area and Ground-Based Data}

Our general study area is the Ontario Province, Canada. Ontario is one of the most industrialized provinces, and holds the most population of the country. The terrain in the province is very smooth with an absence of any mountainous area, making air pollutants easily transported around. Although levels for most of the common air pollutants have been reduced significantly during the past three decades across Canada, air pollution continues to be a serious concern to Ontario, especially for pollutants such as fine PM which continues to exceed standards and impact considerable portions of the general population (Yap et al., 2005). Based on 2003 demographics, Ontario is burdened with 9.6 billion in health and environmental damages each year due to the impact of fine PM and ground ozone, which are associated with smog. The latest studies indicate that the areas of southern Ontario experience the highest levels of acidic deposition, ground-level ozone, fine PM and hazardous air pollutants in eastern Canada (Yap et al., 2005).

Ontario Ministry of the Environment has been monitoring seven pollutants ( $\left.\mathrm{PM} 2.5, \mathrm{SO}_{2}, \mathrm{NO}, \mathrm{NO}_{2}, \mathrm{NO}_{\mathrm{x}}, \mathrm{CO}, \mathrm{O}_{3}\right)^{*}$ for many years through its monitoring network of air quality.

\footnotetext{
*Sulphur Dioxide (SO2), Nitrogen Dioxide (NO2), Total Reduced Sulphur (TRS) Compounds, Carbon Monoxide (CO), Ozone (O3), Fine Particulate Matter (PM2.5) as measured by TEOM operated at 30 degrees $\mathrm{C}$ with a Sample Equilbration System (SES).
} 
The network consists of thirty seven monitoring stations of air quality across the province. Figure 1 illustrates the location of these monitoring stations in Ontario Province. Most of monitoring stations are located in the southern part of the province. There is no station up in the northern rural area. The city of Toronto has the most monitoring stations of four. The city of Hamilton and the city of Windsor have three and two stations located in respectively. All the rest cities have only one station. All the stations have the capability of measuring the concentration of various particulate and gaseous air pollutants at the ground level. Most relevant to this study is the monitoring of PM2.5 and GOC. The stations are designed to record the pollutant variables on an hourly basis.

\subsection{Satellite Data}

The satellite data used in this research are products from the Moderate Resolution Imaging Spectroradiometer (MODIS). MODIS is the key sensor aboard the Terra and Aqua satellites of NASA Earth Observing System (EOS). It is an optical scanner that observes the Earth in 36 channels with spatial resolution ranging from 250 meters to 1 kilometre. MODIS is designed to produce a wide variety of information about the three spheres that human life depends on: Land, Oceans, and Atmosphere. The MODIS science team has consequently developed three groups of products (Atmosphere, Ocean, and Radiometric/Geolocation). The MODIS Atmosphere products are provided in data level 2 and 3 according to the DAAC* data level scheme (Savtchenko et al., 2004). Specifically, the data products used in this study include:

MYD04_L2: A MODIS/Aqua atmosphere product of level 2 providing retrieved ambient Aerosol Optical Depth (AOD), Mass Concentration over Land (MCL), Transmitted Fluxes, and so on at a spatial resolution of $10 \mathrm{~km}$. The algorithms used to extract these products can be found at Menzel et al. (2002) and Kaufman and Tanre (1998). This study includes MYD04_L2 data daily for July, August, November, and December 2003. Totally 123 scenes were selected and ordered from the MODIS Data Ordering Page. All of them were acquired in day.

MYD07_L2: A MODIS/Aqua atmosphere product of level 2 providing Daily global Total Ozone Burden (TOB), Atmospheric Stability, Temperature and Moisture Profiles and Atmospheric Water Vapor at $250 \mathrm{~m}$ and $1 \mathrm{~km}$ resolution. The MYD07_L2 data was collected for the same time periods as above. For each day investigated, two scenes of MYD07_L2 were selected and ordered with one acquired in day and the other at night.

\subsection{Satellite Data Pre-Processing}

The MODIS data is originally provided in HDF format. HDF is a multi-object file format for sharing scientific data in multi-platform distributed environments. There are 53 gridded parameters stored as a Scientific Data Set (SDS) within the

\footnotetext{
*Distributed Active Archive Center (DAAC)
}

MYD04_L2 HDF file. AOD (the parameter "Optical_Depth LLand_And_Ocean") is the MYD04 science parameter that needs to be extracted in this research. This variable measures aerosol optical thickness at $0.55 \mu \mathrm{m}$ for both ocean (best) and land (corrected). For a MYD07_L2 HDF file, there are 28 grided parameters stored within it. Total Ozone Burden (TOB) is the parameter of interest. The MODIS TOB is an estimate of the total-column tropospheric and stratospheric ozone content.

To display and analyze the satellite data, a $\mathrm{HEG}^{* *}$ tool was used to convert all the HDF files into GeoTIFF images. The tool allows users to select a parameter of interest and output it into a GeoTIFF image with a specified projection. So, individual images of AOD and TOB were created for each day by converting their corresponding HDF files. Although MODIS images cover a large region, only the information at the stations is needed for performing a ground-satellite analysis. The values at the stations were extracted from each of the images. The extracted MODIS values were then paired with the corresponding ground-based measurements taken within the same hour as the satellite image. More specifically, AOD was paired with coincident hourly PM2.5, while TOB was paired with hourly GOC.

\section{Analysis of Entire Network}

Correlation analysis was performed between the satellite observations and the ground-based measurements. To examine correlations over the entire network in general, all the stations were taken into consideration at this point. The paired data was categorized into summer and winter groups according to their seasons of acquisition. As the MYD07_L2 data was available for not only day but also night, the correlations between TOB and GOC were further broken down into more specific examinations according to day/night shift. The total number of valid pairs of satellite observation and ground measurements used for each correlation analysis were listed in Table 1 .

Table 1. Correlations across All the Stations

\begin{tabular}{cllcc}
\hline $\begin{array}{c}\text { Variable } \\
\text { Pair }\end{array}$ & Season & Shift & Correlation & $\begin{array}{c}\text { Number of } \\
\text { Valid Pairs }\end{array}$ \\
\hline $\begin{array}{c}\text { PM2.5 } \\
\text { vs. AOD }\end{array}$ & Summer & Day & 0.575 & 319 \\
& Winter & Day & $0.103^{*}$ & 182 \\
GOC vs. & Summer & Day & -0.192 & 904 \\
TOB & & & & \\
& Summer & Night & -0.287 & 642 \\
& Winter & Day & 0.440 & 309 \\
& Winter & Night & 0.447 & 184 \\
\hline
\end{tabular}

* The correlations are significant at the 0.001 level (2-tailed) except for the one with * sign

\footnotetext{
**HDF-EOS to GeoTIFF conversion tool (HEG)
} 
Table 1 also summarizes the correlations studied. Over all, AOD is most strongly related with the coincident hourly $\mathrm{PM}$ 2.5. It is noticed that AOD and PM2.5 are related far stronger in summer than in winter, in which they are nearly independent. In summer, the correlation between PM2.5 and AOD is 0.575 , while the correlation is only 0.103 in the winter, although the numbers of valid data pairs are very close for the summer and the winter analyses. So statistically, AOD may be a good indicator of PM2.5 only in summer. TOB and coincident hourly GOC have shown their fairly strong correlation in winter than in summer over both day and night. TOB and coincident hourly GOC seem independent over both summer and winter.

\section{Site Specific Analysis}

The aggregation performed over all cities tends to even off the correlation variation across the region. It is understandable that the satellite measurements and ground-monitoring data are not related in the same way at all stations. The correlations between AOD vs. PM2.5 and GOC vs. TOB may be high in some geographical areas but low in others. More detailed examination was performed to focus on individual stations in the summer day for AOD vs. PM2.5 and the winter night for GOC vs. TOB, which were found to be highly cor- related in the previous overall analysis. For each station, a number of correlations between AOD vs. PM2.5 and GOC vs. TOB were calculated to show how strong the satellite readings and the ground measurements are correlated for a specific station. All station-oriented correlations are summarized in Table 2.

It is noticed that correlations of AOD and PM2.5 varied widely from the highest correlation of 0.949 at the Simcoe to the lowest correlation of -0.119 at the Torono East. AOD and PM2.5 are very strongly correlated with each other, especially in summer, at most stations. For example, the correlations of AOD and PM2.5 at stations of London, Port Stanley, Simcoe, Belleville, Cornwall, Peterborough, Sault Ste. Marie and Oshawa are significant at values of over 0.8. Among 37 stations examined, 25 of them has a correlation higher than 0.5 . It is unclear why some stations had high correlation than others. It is interesting to see that the four monitoring stations at the downtown, east, north and west of Toronto showed correlations of $0.748,-0.119,0.637$, and 0.235 , respectively. One likely reason for this would be the effect of local pollution sources. The major industrial pollution sources are located at the east and west of Toronto.

Although not showing as strong correlation with GOC as AOD with PM2.5, TOB seems still a good indicator of GOC

Table 2. Correlation Analysis between Satellite Measurement and Ground Data by Monitoring Station

\begin{tabular}{|c|c|c|c|c|c|c|c|}
\hline Station No. & City/Town & AOD vs. PM2.5 & TOB vs. GOC & Station No. & City/Town & AOD vs. PM2.5 & TOB vs. GOC \\
\hline 12008 & $\begin{array}{l}\text { Windsor } \\
\text { downtown }\end{array}$ & 0.371 & 0.243 & 35125 & Toronto west & 0.235 & 0.605 \\
\hline 12016 & Windsor west & 0.568 & 0.013 & 44008 & Burlington & 0.720 & 0.463 \\
\hline 13021 & Merlin & 0.752 & 0.340 & 44017 & Oakville & 0.185 & 0.556 \\
\hline 14064 & Sarnia & 0.393 & 0.169 & 45025 & Oshawa & 0.900 & 0.675 \\
\hline 15020 & Grand bend & 0.738 & 0.293 & 46089 & Brampton & 0.697 & 0.656 \\
\hline 15025 & London & 0.828 & 0.390 & 46110 & Mississauga & 0.429 & 0.629 \\
\hline 16015 & Port stanley & 0.958 & 0.502 & 47045 & Barrie & 0.676 & 0.640 \\
\hline 18007 & Tiverton & 0.450 & 0.047 & 48006 & Newmarket & 0.726 & 0.789 \\
\hline 22071 & Simcoe & 0.949 & 0.466 & 49005 & Parry sound & 0.771 & 0.244 \\
\hline 26060 & Kitchener & 0.308 & 0.673 & 49010 & Dorset & 0.226 & 0.148 \\
\hline 27067 & St. Catharines & 0.505 & 0.475 & 51001 & Ottawa & 0.734 & 0.446 \\
\hline 28028 & Guelph & 0.049 & 0.574 & 52020 & Kingston & 0.563 & 0.469 \\
\hline 29000 & $\begin{array}{l}\text { Hamilton } \\
\text { downtown }\end{array}$ & 0.630 & 0.678 & 54012 & Belleville & 0.837 & 0.563 \\
\hline 29114 & $\begin{array}{l}\text { Hamilton } \\
\text { mountain }\end{array}$ & 0.729 & 0.591 & 56051 & Cornwall & 0.861 & 0.441 \\
\hline 29118 & Hamilton west & 0.677 & 0.737 & 59006 & Peterborough & 0.824 & 0.638 \\
\hline 31103 & $\begin{array}{l}\text { Toronto } \\
\text { downtown }\end{array}$ & 0.748 & 0.615 & 63200 & Thunder Bay & 0.483 & -0.071 \\
\hline 33003 & Toronto east & -0.119 & 0.567 & 71068 & Sault Ste. Marie & 0.882 & -0.223 \\
\hline 34020 & Toronto north & 0.637 & 0.791 & 75010 & North bay & 0.773 & -0.136 \\
\hline 77203 & Sudbury & $\mathrm{N} / \mathrm{A}$ & -0.033 & & & & \\
\hline
\end{tabular}



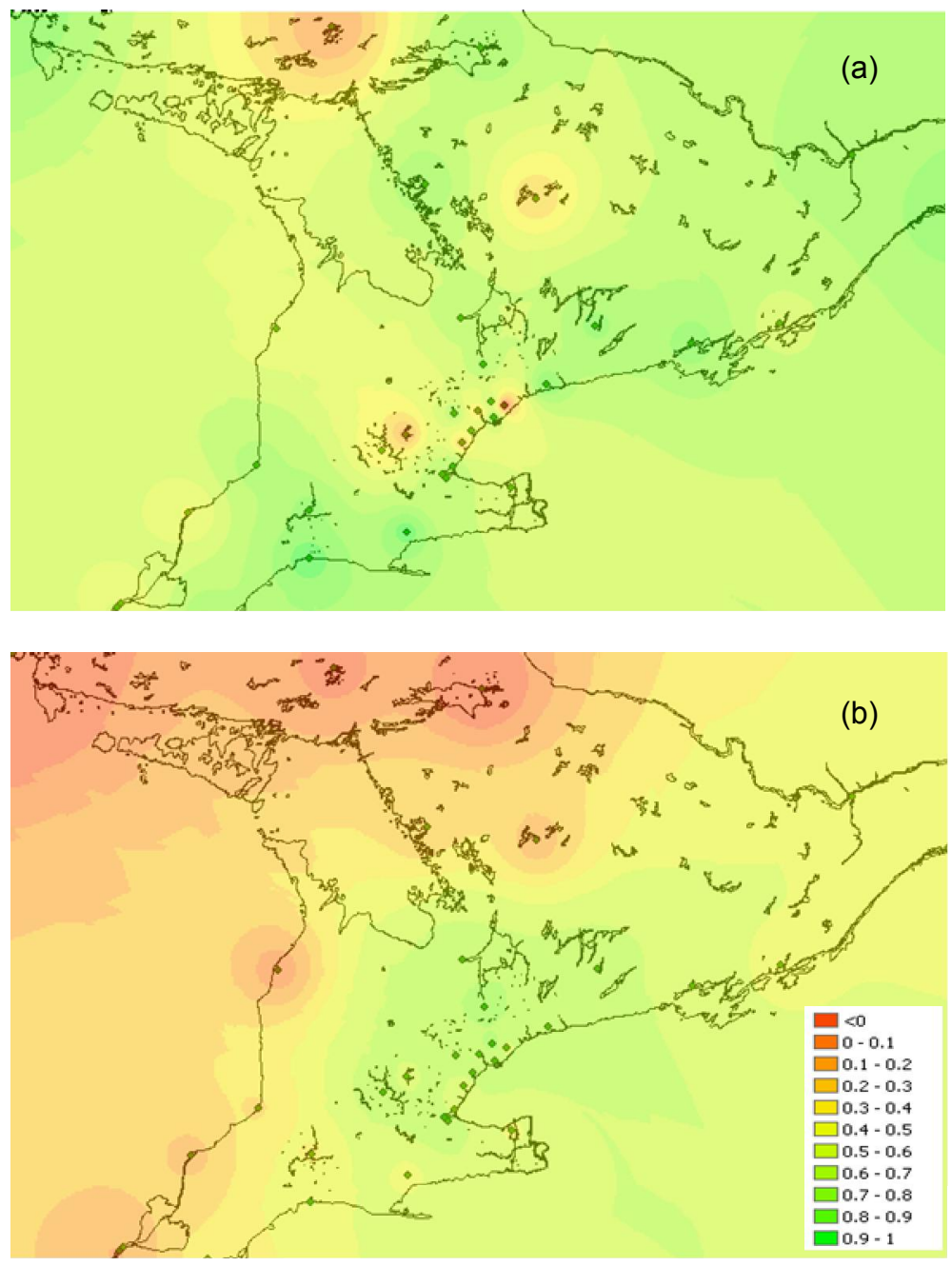

Figure 2. Correlation between (a) AOD and PM2.5 in the summer day; (b) TOB and GOC in the winter day.

at some places. There are more cities or towns where the corresponding satellite readings can not be directly used to tell the ground pollutant condition simply because of their weak correlations calculated. Interestingly, there are some negative correlations recognized which should be carefully examined because they are very likely to be misleading. It is argued that the negative correlations could be due to a number of factors including more frequent occurrence of atmospherically elevated haze, errors in the MODIS cloud masking of low stratus clouds, or poor model assumption (Engel-Cox et al., 2004). Further analysis and validation is needed to examine the site pollution source and land use conditions in order to fully understand the relationship between satellite and ground measurements.

The smoothed spatial surfaces of correlation illustrated in Figure 2 were constructed for AOD vs. PM2.5 (Figure 2a) and TOB vs. GOC (day) (Figure 2b) by interpolating correlation coefficients at the points of monitoring stations by using the inverse distance weighted approach for the south part of Ontario. The variation of correlations is clearly illustrated in Figure 2. From Figure 2 it is apparent that the correlations are not on a same level of strength across the region. However, it should be noted that this correlation surface is interpolated from only 37 stations. The correlation values in the map surface may not represent the actual relationship of ground measurements and satellite data. It is obvious that interpolated correlation surfaces from the current monitoring points are not enough to check the internal pattern within the Great Toronto region.

In order to compare spatial patterns of PM2.5 and GOC obtained from ground monitoring station with those of AOD and TOB from MODIS, the TOB and GOC surface from MODIS are displayed along with the interpolated surface of PM2.5 and GOC. Figure 3 illustrates an example of the TOB surface directly obtained from remotely sensed data (Figure 3a) and the GOC interpolated surface from monitoring sta- 


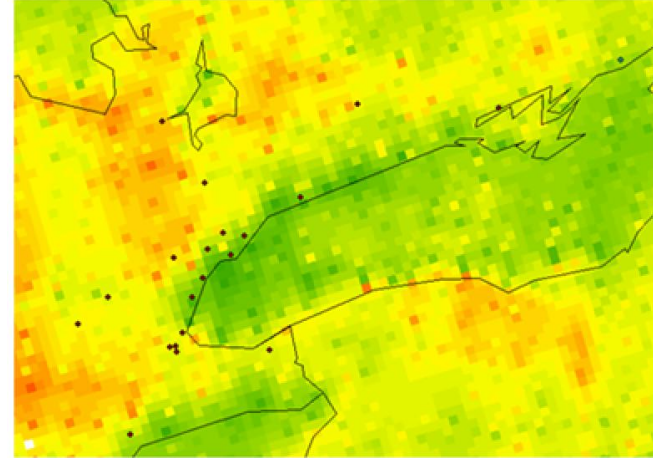

(a)

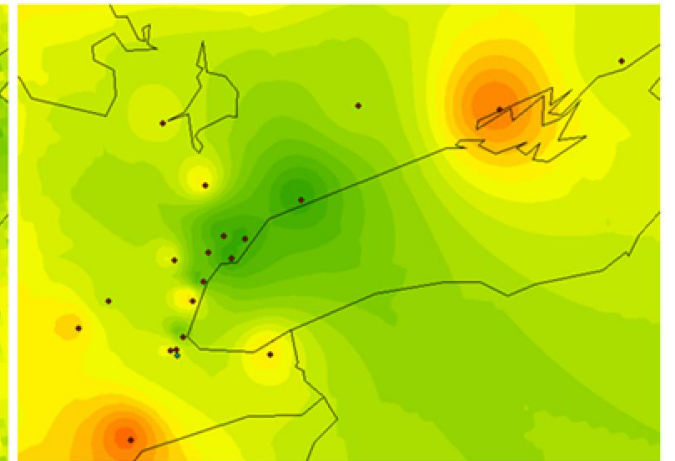

(b)

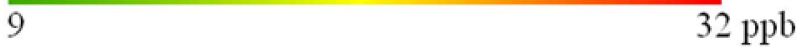

Figure 3. An example of the ozone concentration surface (a) obtained from MODIS satellite data, and (b) interpolated from ground monitoring stations on July 15, 2003.

tions (Figure 3b) for the night of July 15, 2003 using the inverse distance weighted approach. From Figure 3a, the impact of land surface and land use on the concentration of ozone can be seen clearly. The atmosphere above the lake has a lower TOB concentration than those over the land surface. The high concentration of ozone appears in the surface of inland urban and agriculture areas. This pattern can not be seen from the interpolated surface from the limited ground-based measurements although the measurements obtained at the monitoring stations had a strong and high correlation of 0.72 , with corresponding values extracted from MODIS satellite data.

\section{Conclusions}

This paper evaluates the correlation between the pollutant concentration measurements from the Moderate Resolution Imaging Spectroradiometer (MODIS) satellite data and the ground measurement. The atmospheric parameters of total ozone burden (TOB) and aerosol optical depth (AOD) were compared with the ground-based measurements of ozone concentration (GOC) and the fine particular matter (PM2.5), respectively for the Ontario Province, Canada. The results showed that AOD was most strongly related with coincident hourly PM2.5 in summer. It was found that the correlation between AOD and PM2.5 were nearly independent in summer from those in winter. TOB and coincident hourly GOC have shown their fairly strong correlation in winter over both day and night, with the correlation of TOB and GOC slightly stronger in winter night.

This is the first study to demonstrate that the correlation between the satellite measurement and ground monitoring data varied in different seasons. It is unclear why the correlation between ground monitoring data and satellite measurements is higher at some stations than others. Further analysis and validation is needed to examine the site pollution source, land use and weather conditions in order to fully understand the relationship between satellite and ground measurements. It was found that the current number and locations of ground monitoring stations were not enough to catch the regional air quality changes. The air quality distribution obtained from satellite images had a much better correspondence with the regional morphology than those interpolated from ground measurements. The MODIS has great potential to support and enhance the air quality monitoring network for areas without ground monitoring stations, and provide regional-scale air pollution patterns. The future validation of remotely sensed measurement should be conducted by extensive ground-truth campaign within the region in order to make better use of satellite measurements

Acknowledgments. This research was supported by a grant from the Best in Science program, Ontario Ministry of Environment. The authors would like to thank Melynda M. Bitzos for providing ground air pollution data and Dan Orr for his support for this research. The data used in this study were acquired as part of the NASA's Earth Science Enterprise. The algorithms were developed by the MODIS Science Teams. The data were processed by the MODIS Adaptive Processing System (MODAPS) and Goddard Distributed Active Archive Center (DAAC), and are archived and distributed by the Goddard DAAC.

\section{References}

Arya, S.P. (1998). Air Pollution Meteorology and Dispersion, Oxford University Press, New York

Briggs, D.J. (1992). Mapping environmental exposure, in P. Elliott, J. Cuzick, D. English and R. Stern, Geographical and Environmental Epidemiology: Methods for Small-area Studies, Oxford University Press, Oxford, pp. 158-176.

Engel-Cox, J.A., Holloman, C.H., Coutant, B.W. and Hoff, R.M. (2004). Qualitative and quantitative evaluation of MODIS satellite sensor data for regional and urban scale air quality. Atmos. Environ., 38, 2495-2509.

Hameed, S. (1974). Modelling urban air pollution. Atmos. Environ., 8 , $555-561$.

Hass, H., Builtjes, P.J.H., Simpson, D. and Sternii, R. (1997) Comparison of model results obtained with several European re- 
gional air quality models. Atmos. Environ., 31(19), 3259-3279.

Hutchison, K.D., Smith, S. and Faruqui, S. (2004). The use of MODIS data and aerosol products for air quality prediction. Atmos. Environ., 38, 5057-5070.

Hutchison, K.D., Smith, S. and Faruqui, S.J. (2005). Correlating MODIS aerosol optical thickness data with ground-based PM2.5 observations across Texas for use in a real-time air quality prediction system. Atmos. Environ., 39, 7190-7203.

Kaufman, Y. J. and Tanre, D. (1998). Algorithm for remote sensing of tropospospheric aerosols from MODIS. Mod04 ATBD Document.

McRae, G.J., Goodin, W.R. and Seinfeld, J.H. (1982). Development of a second-generation mathematical model for urban air pollution: I. Model formulation. Atmos. Environ., 16, 679-696.

Morris, R.E. and Myers, T.C. (1990). User's Guide to the Urban Airshed Model, US Environmental Protection Agency, Research Triangle Park, NC I-V.

Savtchenko, A., Ouzounov, D., Ahmad, S., Acker J., Leptoukh G., Koziana J., and Nickless, D. (2004). Terra and Aqua MODIS products available from NASA GES DAAC. Adv. Space Res.:
Trace Constituents in the Troposphere and Lower Stratosphere, 34(4), 710-714.

Ulke, A.G. and Andrade, M.F. (2001). Modeling urban air pollution in Sao Paulo, Brazil: Sensitivity of model predicted concentrations to different turbulence parameterizations. Atmos. Environ., 35, 1747-1763.

Ung, A., Wald, L., Ranchin, T., Weber, C., Hirsch, J., Perron, G., and Kleinpeter, J. (2003). Air pollution mapping: Relationship between satellite-made observations and air quality parameters, in Proc. of 12th International Symposium "Transport and Air Pollution", Arcueil, France, pp. 105-112.

Villasenor, R., Claiborn, C., Lamb, B. and O'Neill, S. (2001). Mesoscale modeling of wintertime particulate matter episodes in eastern Washington, USA. Atmos. Environ., 35, 6479-6491.

Wald, L. (1999). Observing air quality over the city of Nantes by means of Landsat thermal infrared data. Int. J. Remote Sens., 20 (5), 947-959.

Yap, D., Reid, N., De Brou, G. and Bloxam, R. (2005). Transboundary air pollution in Ontario, Ontario Ministry of the Environment, Toronto, pp. 123. 